\title{
Revista Brasileira de Enfermagem REBEn \\ A constituição dos modos de perceber a loucura por alunos e egressos do Curso de Graduação em Enfermagem: um estudo com o enfoque da Fenomenologia Social
}

The constitution of the ways students and egresses of a Nursing Course percieve madness: a study with the approach of Social Phenomenology

La constitución de los modos de percibir la locura por alumnos y egresos del Curso de Enfermería: un estudio con el enfoque de la Fenomenología Social

\section{Silvana Chorratt Cavalheri}

Enfermeira. Professor

Doutor da Faculdade de Enfermagem do Centro de Ciências da Vida da Pontifícia Universidade Católica de Campinas, SP. silvanac@puc.campinas.edu.br

Míriam A. Barbosa Merighi

Livre Docente da Escola de Enfermagem da Universidade de São Paulo, SP.

Orientador da Tese. merighi@usp.br

Maria Cristina Pinto de Jesus

Enfermeira. Professor Doutor da Universidade Federal de Juiz de Fora, MG.

Trabalho extraído da tese de Doutorado apresentado à Escola de Enfermagem da Universidade de São Paulo.

Submissão: $12 / 06 / 2006$

Aprovação: $23 / 10 / 2006$

\section{RESUMO}

Estudo qualitativo com enfoque na Fenomenologia Social que teve como objetivo conhecer a percepção dos alunos de graduação e egressos de uma Escola de Enfermagem sobre o doente mental e, compreender de que forma 0 ensino de enfermagem psiquiátrica repercute nesse processo. 0 "tipo vivido aluno" percebe o doente mental como uma pessoa diferente, violenta, sem controle, que perde a razão, sem habilidades e condições de viver socialmente, que desperta emoções conflitantes como medo, preconceito e compaixão. 0 egresso o concebe como uma pessoa que precisa de ajuda, pois a falta de conhecimentos, de recursos psíquicos e emocionais dos profissionais, das famílias e da sociedade favorece a segregação e a exclusão. Assim, o ensino, necessita da prática subsidiada teoricamente pelos eixos que sustentam os princípios da Reforma Psiquiátrica.

Descritores: Enfermagem psiquiátrica; Estudantes de enfermagem; Psiquiatria.

\section{ABSTRACT}

Qualitative study with the approach of the Social Phenomenology that had as objective to know graduation students and egresses of a Nursing School percieve mental patient and, to understand how the education of psychiatric nursing reflects in this process. The "living student-type" perceives the mental patient as a different person, violent, without control, who loses the reason, without abilities and conditions of living socially, who awakes conflicting emotions as fear, prejudice and compassion. The egresses have mental patients as a person who needs help, because the lack of knowledge, psychic and emotional resources of the professionals, the relatives and the society favors the segregation and the exclusion. Thus, the education needs the practice subsidized theoretically by the axes that support the principles of the Psychiatric Reformation.

Descriptors: Psychiatric nursing; Education, nursing; Psychiatry.

\section{RESUMEN}

Estudio cualitativo con enfoque en la Fenomenología Social que tuvo como objetivos conocer la percepción de los alumnos de graduación y los egresos de una Escuela de Enfermería sobre el enfermo mental y, comprender de que forma la enseñanza de enfermería psiquiátrica repercute en ese proceso. La tipificación muestra que el alumno ve al enfermo mental como una persona diferente, violenta, sin el control, que pierde la razón, sin habilidades y condiciones de vivir socialmente, que despierta emociones conflictantes como miedo, prejuicio y comparación. El egreso lo concibe como una persona que necesita ayuda, pues la falta de conocimientos, de recursos psíquicos y emocionales de los profesionales, de las familias y de la sociedad favorecen la segregación y la exclusión. Así, la enseñanza necesita la práctica subvencionada teóricamente por los ejes que sostienen los principios de la Reforma Psiquiátrica. Descriptores: Enfermería Psiquiátrica; Educación en enfermería; Psiquiatría.

Cavalheri SC, Merighi MAB, Jesus MCP. A constituição dos modos de perceber a loucura por alunos e egressos do Curso de Graduação em Enfermagem: um estudo com o enfoque da Fenomenologia Social. Rev Bras Enferm 2007 jan-fev; 60(1):9-14.

\section{CONSIDERAÇÕES INICIAIS}

Percebe-se que o início da vivência de aprendizado de Enfermagem Psiquiátrica e o conseqüente contato com o doente mental, na maioria das vezes, é experienciado pelo graduando como algo de difícil compreensão, de difícil aceitação e de difícil manejo.

Inicialmente há uma resistência intensa por parte do aluno a viver esta situação de aprendizado, por uma leitura estigmatizada desse tipo de sujeito - o louco (neste estudo, os termos loucura e louco estão sendo utilizados como sinônimos de doença mental e doente mental) e pelos contextos em que 
ocorrem estas assistências - instituições psiquiátricas e ou serviços de Saúde Mental.

Com o passar dos dias, envolvido nesse processo de aprendizagem e interação ocorre uma mudança na percepção e na aceitação do aluno em relação ao doente mental, o que, em parte, provavelmente é favorecida pela aquisição de novos conhecimentos e pela possibilidade de desmistificar muitas fantasias que envolvem a loucura e também pelo contato real e concreto com as pessoas que passam pela experiência de ter uma doença mental.

Neste sentido, o convívio com os alunos em períodos que antecedem seu aprendizado em relação à doença mental, quando vivenciam esta experiência, e em fases posteriores, permite-nos crer que a transformação da percepção que têm do louco, só ocorre na fase do aprendizado. A maioria, logo após, retoma a mesma atitude e o mesmo discurso estigmatizado em relação ao doente mental.

Este processo é bastante distinto do que se verifica com as demais doenças, as não mentais, como se, nesta última, a relação com a doença e o doente fosse determinada prioritariamente pela compreensão cognitiva, o que parece não ser verdadeiro no caso da doença mental.

A assistência a pessoas mentalmente enfermas desperta emoções inconscientes. Cuidar de pacientes psiquiátricos evoca ansiedade que se reflete, inclusive, na qualidade do atendimento. 0 esforço que a reabilitação desses pacientes envolve, faz com que as enfermeiras que acompanham pacientes com internações prolongadas, muitas vezes, mudem seu comportamento, comportamentos estes que parecem servir como proteção da equipe para a ansiedade inconsciente que o trabalho provoca, podendo ser entendidos como três formas básicas de ansiedade: medo da loucura e da perda de controle, da severidade das suas limitações e vulnerabilidades e a cronicidade de suas dificuldades ${ }^{(1)}$.

A percepção desses sentimentos ocultos inquieta-nos e suscita diversos questionamentos que vão de uma elaboração mais objetiva e concreta a uma mais subjetiva, individual e também social. Baseando-nos neste olhar, elaboramos alguns questionamentos que motivaram a realização desta pesquisa: qual a percepção que os acadêmicos de Enfermagem têm a respeito do doente mental? Qual o fenômeno que consubstancia a visão excludente e discriminatória que possuem do doente mental? Quais os aspectos subjetivos que permeiam esta visão? O conhecimento formal das doenças mentais possibilita a transformação desta visão? Há mudanças na compreensão/atitude dos acadêmicos, após cursarem disciplinas de saúde mental?

Nesta perspectiva do doente mental, tomado como SER que amedronta e desperta a rejeição das pessoas, independente da história vivida por elas, do nível escolar e da área de formação, realizamos este estudo com o objetivo de conhecer como é constituída a percepção que o aluno de graduação e egresso de Enfermagem tem sobre o doente mental e compreender de que forma o ensino de Enfermagem Psiquiátrica repercute nesse processo.

\section{O REFERENCIAL TEÓRICO METODOLÓGICO DE ALFRED SCHUTZ}

0 mundo da vida cotidiana é o mundo em que o homem atua diariamente, intervindo e modificando-o, conforme seus interesses práticos, expressos por meio do corpo, por suas ações, movimentos e reações ${ }^{(2)}$.

Compreender, o mundo da vida, segundo uma visão global, é compreendê-lo como mundo natural e social, entendendo este último também como mundo cultural. Aqui se fala do mundo onde há atuação, movimento, onde são exercidas as ações, mundo dos semelhantes, das ações conjuntas e dos limites. Mundo onde se dá a vivência, intersubjetiva, e são estabelecidas as relações com os outros.

No mundo da vida, cada homem possui sua própria história, vive em uma cultura, traz consigo um corpo de conhecimento e experiências decorrentes de seu modo de viver. É, portanto, alguém que enxerga o mundo por uma perspectiva diferente de seu semelhante. A este modo próprio de inserção no mundo, dá-se a denominação de situação biográfica(2).

A sedimentação das experiências do indivíduo, adquiridas ao longo da vida, é denominada pela bagagem de conhecimentos disponiveis. Tratase de uma estrutura sedimentada das experiências vivenciadas ou comunicadas por outras pessoas ${ }^{(2)}$

Da experiência armazenada e do estoque de conhecimentos que tem à mão, é que o indivíduo orienta-se nas situações de vida. Esses conhecimentos provêm de suas experiências vivenciadas ou a ele transmitidas por seus familiares, mestres e, de modo geral, pelos mais velhos com os quais se relacionou. Funcionam como "receitas" que são armazenadas desde a infância e que serão utilizadas nas situações da vida cotidiana conforme se fizerem necessárias ${ }^{(2)}$.

Neste mundo da vida cotidiana, que também é um mundo cultural de significações, o indivíduo realiza suas ações. A designação que o indivíduo dá à sua ação, bem como o sentido que a ação tem para ele, é a de ação social (2).

Ao investigar os impulsos subjetivos da ação humana, Schutz encontra a teoria da motivação e revela-nos o duplo caráter da motivação, fundamentada em motivos para/motivos a fim de e motivos porque. Os "motivos para" são aqueles que levam os homens a executarem ações que se projetam no futuro. No decorrer da experiência de desenvolver uma ação, de acordo com seu plano preconcebido, o ator vivência diretamente os seus "motivos a fim de". Estes são, portanto, essencialmente subjetivos ${ }^{(2,3,4,5)}$

Os "motivos porque" estão enraizados em experiências passadas, enquanto os atores agem, não os têm no nível da consciência.

Com base nas próprias percepções e definições, as pessoas criam tipos no mundo do senso comum, de acordo com seus critérios subjetivamente significativos.

Schutz desenvolveu seus estudos com a inquietação proveniente da compreensão do significado subjetivo da ação, o que irá possibilitar construir 0 tipo vivido, considerando-se que 0 ator social tipifica o mundo para compreendê-lo e comunicar-se com seu semelhante ${ }^{(4)}$.

A tipificação é um meio de chegar-se a um acordo com o mundo, sem descrever na realidade suas qualidades reais ou essenciais. Os tipos não existem por si mesmo, sob forma pura e simples, mas são conceitos relativos que expressam motivos particulares e interesses de indivíduos específicos que definem seus ambientes e dão significados ao mundo, emergem na experiência cotidiana como pressupostos que fazem parte da herança sociocultural transmitida aos membros de um grupo interno em um processo educacional, aceitos sem julgamentos, funcionando como código de interpretação e orientação(6)

\section{ENCAMINHAMENTO METODOLÓGICO}

O desenvolvimento deste trabalho dentro da abordagem fenomenológica mostrou-se mais coerente em razão de essa abordagem possibilitar o desvelar do vivido pelo sujeito, ir ao encontro do fenômeno como percebido na consciência do indivíduo, valer-se do princípio da intencionalidade, em que consciência é sempre "consciência de alguma coisa".

Para desenvolver esta proposta, sentimos necessidade de utilizar um referencial teórico-metodológico que orientasse e dessa sustentação a este caminhar, na consideração de que nos propomos a investigar questões que ocorrem no mundo do cotidiano, que implicam condutas constituídas subjetivamente e vivenciadas nas relações interpessoais, adquirindo, assim, um caráter de intersubjetividade. Estas experiências, mesmo que vivenciadas individualmente, com atribuição de significado próprio, situamse dentro do contexto de intersubjetividade, configurando, desta forma, um grupo social. 
A constituição dos modos de perceber a loucura por alunos e egressos do Curso de Graduação em Enfermagem: um estudo com o enfoque da Fenomenologia social

Optamos por utilizar a abordagem fenomenológica da Sociologia Compreensiva de Alfred Schultz, considerando que nesta abordagem não importa investigar o comportamento individual, particular de cada ator; 0 foco de interesse é o que pode constituir-se como uma característica típica de um grupo social que vive uma determinada situação.

Para o desenvolvimento desta pesquisa, foi utilizada como região de inquérito a Faculdade de Enfermagem de uma Universidade particular do interior do Estado de São Paulo, local de onde emergiram as inquietações que buscamos desvelar com este estudo.

Os sujeitos do estudo foram os alunos ingressantes da graduação de Enfermagem, sendo sete do sexo feminino e dois do masculino, com idade entre 19 e 41 anos, que não haviam tido ainda contato com disciplinas da área da Saúde Mental, portanto, pessoas que ainda não haviam adquirido conhecimentos formais específicos de Enfermagem Psiquiátrica. Neste sentido, buscamos captar as idéias que foram sendo constituídas em seu mundo-vida a respeito do doente mental, considerando que este cenário possibilitaria chegar-se às representações significativo - simbólicas desses indivíduos, que representam a base das tipificações por eles elaboradas.

Também participaram da pesquisa alunos egressos da Faculdade de Enfermagem, em número de dez pessoas, sendo todas do sexo feminino com idade variando entre 24 e 35 anos, ou seja, enfermeiros graduados pela instituição que já haviam cursado as disciplinas que compõem, nesta instituição, a área da Saúde Mental (Psicologia I, Psicologia II, Saúde do Adulto Enfoque Saúde Mental e Saúde do Adulto Enfoque Enfermagem Psiquiátrica).

O número de participantes foi definido no transcorrer da coleta de dados com base no momento em que houve convergência no discurso dos sujeitos da pesquisa, isto é, os discursos tornaram-se repetitivos para a elucidação do fenômeno.

Para apreender a essência do fenômeno pesquisado neste estudo, foi utilizado como recurso de coleta de dados entrevistas individuais, com questões não diretivas, criando-se condições para que os sujeitos se expressassem livre e espontaneamente, relatando suas vivências de forma precisa e descritiva, como por eles percebidas.

Para se chegar ao egresso foram selecionadas duas instituições hospitalares que conhecidamente contam com um grande número de egressos da Faculdade de Enfermagem, referência para este estudo.

Quanto aos alunos, foram abordados nas dependências da Faculdade, em espaços privados, onde tomaram contato com o Termo de Consentimento Informado e Esclarecido. As entrevistas com os egressos foram realizadas nas dependências da instituição na qual estavam vinculados e foram gravadas com o conhecimento e autorização dos sujeitos, respeitando 0 estabelecido nas normatizações éticas, referentes à Resolução 196/96 do Conselho Nacional de Saúde, todos os sujeitos que foram convidados aceitaram participar do estudo.

Foram elaboradas três questões norteadoras, sendo a última feita somente aos egressos da Faculdade, por envolver vivências ainda não experimentadas pelos outros sujeitos.

Doente Mental - quando você ouve esta palavra que imagens the vêm à mente; como foi sendo constituída ao longo de sua vida esta percepção que você tem do doente mental; após ter cursado a disciplina de Enfermagem Psiquiátrica, houve alteração na sua percepção em relação ao doente mental?

Todos os depoentes tiveram garantido o anonimato e o sigilo quanto a sua identificação, uma vez que os discursos foram identificados por números arábicos, não sendo desta forma, usado o nome dos depoentes. O número arábico foi precedido pela letra e quando se tratava do aluno e pela letra eg quando se referia ao egresso.

Para compreender o significado da ação vivenciada por alunos e egressos de Enfermagem em relação ao doente mental, por meio da tipologia do vivido, percorremos as etapas recomendadas por Capalbo, que prevêem: realização de entrevista fenomenológica como recurso para a obtenção das descrições; utilização da análise compreensiva, tendo em vista apreender o significado do vivido pelo sujeito e interpretação com base na compreensão das descrições expressas à luz da Fenomenologia Social(4)

\section{RESULTADOS E DISCUSSÃO}

4.1 Análise Compreensiva dos Discursos dos Alunos Ingressantes

$O$ vivenciar do exercício de familiarização com as falas permitiu aflorar aspectos dos discursos ricos de sentido que representavam unidades que compõem as categorias concretas do vivido.

No primeiro momento, buscamos organizar a convergência dos aspectos comuns que apareciam nos discursos e em um segundo momento, realizamos uma nova etapa de organização de onde emergiram as categorias concretas do vivido.

Procuramos deter-nos de forma atenta ao que se apresentava em comum. Lendo atenciosamente estes conteúdos, percebemos que os mesmos convergiam para cinco grandes temáticas, que foram denominadas categorias concretas do vivido.

As alunas percebem o doente mental como pessoa: diferente na aparência e manifestação corporal e diferente no que tange aos aspectos cognitivos, afetivos e atitudinais que redundaram na categoria percebendo uma pessoa diferente; pessoa que desperta medo, receio e temor que implicou na constituição da categoria pessoas que despertam medo; pessoas que evocam sentimentos de dó, pena e compaixão que resultaram na categoria pessoas que despertam dó e compaixão; pessoas que são discriminadas pela sociedade que culminou na categoria preconceito.

Mantendo um olhar centrado nas categorias percebemos, ainda, que elas confluíam entre si e convergiam para uma grande categoria que mostra o contexto em que foi constituída a percepção que alunos de graduação em enfermagem, sujeitos desta pesquisa, têm do doente mental que resultou na categoria contextualizando a percepção sobre o doente mental.

A constituição das categorias que são apresentadas, a seguir nos remete à compreensão dos motivos para, da ação aqui pesquisada, que se revelam arraigados nos motivos porquê, ou seja, a vivência que constituiu a percepção que os sujeitos têm do doente mental. Com base no que nos foi possível captar, o típico expresso nas falas e constituir o "tipo vivido aluno", no que se refere à percepção que tem do doente mental.

Para a análise dos discursos dos alunos que participaram desta pesquisa, o conceito usado como eixo de sustentação foi a intersubjetividade, uma vez que fenomenologicamente a base de qualquer pesquisa está no mundo cotidiano, no mundo da vida, no mundo pré-reflexivo. Neste é que reside a fonte de significados que é essencial para toda pesquisa, é a partir das experiências neste mundo, que os entrevistados elaboram suas percepções.

Ser Diferente foi o aspecto que se apresentou com destaque em todos os discursos. Os sujeitos quando se referiam ao Doente Mental, em algum momento de suas falas traziam isto como um traço, uma marca desse doente. A categoria percebendo uma pessoa diferente abarcou percepções variadas que envolviam desde diferenças na aparência e manifestação corporal até diferença nos aspectos cognitivos, afetivos e atitudinais.

"Uma pessoa perturbada, bom, eu vejo assim, uma pessoa desorientada, sem uma coisa central, ela toma atitude e faz coisas que não é muito normal...." (e-5)

As expressões dos entrevistados, mesmo que manifestadas, individualmente, representam tipificações que são fundamentadas em uma estrutura social comum. Essas pessoas compartilham o significado subjetivo de pertencer a um grupo que tem a mesma percepção sobre o doente mental, como alguém que é de "outro grupo" de um "grupo existencial" que 
compartilha a herança social de ser diferente, uma vez que o papel e a posição que ocupa na sociedade não é por ele estabelecida, e sim, é a ele outorgada.

Pautadas na análise da categoria, percebendo uma pessoa diferente, começam a delinear-se as tipificações que serão complementadas pelas falas contidas nas demais categorias aqui analisadas.

Em nossa sociedade, quando falamos de doente mental, é comum que em algum momento apareça uma expressão de medo relacionada a ele. Pelo próprio desenvolvimento histórico da psiquiatria e da assistência psiquiátrica, as pessoas através dos tempos foram constituindo em seu imaginário, uma idéia do doente mental como alguém agressivo. Conviver com alguém que é percebido marcado por uma característica de periculosidade leva quase que automaticamente ao desenvolvimento de um sentimento de medo relacionado a ela. Assim, na categoria Pessoas que Despertam Medo os sujeitos desta pesquisa manifestaram-se:

“...a gente fica com medo, quando a gente não conhece, não sabe dos problemas. Eu passei por uma experiência agora, mudou um vizinho meu, que acabou de sair do Hospital Psiquiátrico, e eu fiquei morrendo de medo dele também, porque a gente não sabe se ele é violento, se não é, não sabe até que ponto é doença, ou outra coisa da pessoa..." (e-6)

O mundo do senso comum é interpretado subjetivamente, baseado em nosso acervo de conhecimento e, indiretamente, às tipificações que compreendem esse conhecimento $E$ estas tipificações existem independes de cada indivíduo, como um produto da sociedade que todos aceitam como ponto pacíicico(5)

O conhecimento é necessário para que interpretemos significativamente o mundo, mas, as formas particulares de tipificação sob as quais está organizado, são socialmente derivadas. Este conhecimento aprovado funciona como "receitas sociais", destinadas a permitir aos membros de um grupo que definam suas situações na realidade da vida diária de uma maneira típica. Representam o padrão cultural do grupo a que estão relacionados ${ }^{(2)}$

As "receitas sociais" são, portanto, o elemento mais importante em nossa definição de uma situação e funcionam como legitimadoras de um conhecimento comum, foi delas que os sujeitos desta pesquisa desenvolveram suas percepções de doente mental e assimilaram conteúdos desta receita social, que, secularmente, tem servido como fórmula típica da sociedade para perceber o doente mental como uma regra socialmente aprovada.

As manifestações dos sujeitos a respeito do medo aparecem de forma bastante intensa, representam a fala que permeia todo o discurso em algum momento. No entanto, é interessante percebermos que estes sujeitos referem-se também a uma outra ordem de sentimento quando falam do doente mental, retratando-o como pessoas que despertam dó e compaixão.

“...E eu tenho dó dele estar assim, nesta situação. E fico imaginando porque chega num ponto de desequilibrio de fazer coisas que ele mesmo não consegue controlar..."(e-5)

Apresentar uma doença mental implica na existência da compaixão. Este parece ser é um sentimento contido dentro do código de tipificação dos profissionais que prestam assistência ao indivíduo adoecido, em especial, o enfermeiro. Faz parte de seu sistema de relevância e essa tipificação é originada das vivências do senso-comum, na qual foi atribuída como característica deste profissional a capacidade de ficar "penalizado" com a dor do outro. Para Schutz as tipificações do senso comum - em oposição às feitas pelo cientista e, especialmente, o cientista social, emergem na experiência cotidiana do mundo, como pressupostos, sem qualquer formulação de julgamentos ou proposições claras, com sujeitos e predicados lógicos ${ }^{(5)}$. De complicados desafios na vida, por um lado, há a necessidade de lutar com os sintomas e desabilidades que resultam da doença e, por outro lado, os desafios oriundos dos estereótipos e preconceitos que resultam das interpretações errôneas sobre a doença mental. Nas sociedades modernas, histórica e tradicionalmente, estas têm sido as marcas impressas de forma mais intensa à pessoa que vivencia a experiência da doença mental. Este aspecto também foi bastante destacado nas falas dos sujeitos, como demonstram o discurso a seguir:

"Desde criança, a gente viveu numa sociedade que quando a gente fazia alguma coisa errada, vinha alguém e te falava: "o louco do saco vai te levar embora e você nunca mais vai ver pai, mãe, vai te levar, te judiar..."(e-1)

Mesmo que as pesquisas tenham ido longe para entender o impacto da doença mental, as explicações quanto ao estigma da doença, tem ocorrido mais recentemente. Muito trabalho ainda precisará ser feito para entender totalmente a amplitude e 0 alcance do preconceito contra as pessoas com doenças mentais( ${ }^{(8)}$.

$\mathrm{Na}$ categoria que retrata a contextualização da percepção sobre 0 doente mental, os sujeitos da pesquisa anunciam uma percepção constituída a partir de informações obtidas dos meios de comunicação e também de valores familiares expressos pelos pais que têm uma visão negativa do doente mental e, desta forma, influenciaram seus filhos. Notase que, em seus discursos, trazem a marca do vivido no mundo da atitude natural; do adquirido como bagagem de conhecimento disponivel decorrente de suas situações biográficas:

"A idéia do doente mental ser agressivo ou ser extremo, de forma extrema, eu acho que foi passado de geração em geração. Uma pessoa fala para a outra, como ela é, a gente vê passar na rua. E as pessoas comentam como ela é mesmo sem a gente conhecer, sem viver com ela. ...não é como a pessoa, como a gente, é diferente da gente." (e-3)

As experiências vividas no mundo natural constituem para Schutz 0 que é biográfico de cada sujeito na medida que suas experiências verificamse neste mundo. É da experiência que armazenou e do estoque de conhecimentos que tem à mão que o indivíduo orienta-se nas situações de vida. Estes surgem da estrutura social e dependem da situação exclusiva que ele ocupa no mundo. $O$ ser humano consulta seu estoque de conhecimentos para interpretar suas experiências e observações, definir a situação em que se encontra e fazer planos. Estas experiências, tipicamente apreendidas e interpretadas, servem de base para ações futuras e com freqüência, são utilizadas para efetuações de ações rotineiras. As novas situações são delineadas pelas possibilidades imaginativas dos sujeitos, além do estoque de conhecimentos ${ }^{(2)}$

As percepções foram constituídas baseadas em vivências infantis, da transmissão de valores de seus predecessores e de influência da mídia, resultando num tipo vivido que percebe o doente mental como uma pessoa violenta, sem controle, que perde a razão, que não tem habilidades nem condições de viver socialmente. Enfim, o aluno percebe o doente mental como uma pessoa que é diferente, que desperta medo, dó, compaixão e preconceito.

\subsection{Análise Compreensiva dos Discursos dos Egressos}

A fala dos egressos, à semelhança dos alunos, é rica ao expor a influência de vivências infantis:

"Essa idéia foi sendo constituida pelas pessoas que vinham me falar, a minha própria familia dizia que precisávamos Ter medo do doente mental. Nunca sabemos a reação dele, a gente tem que estar sempre com os pés atrás, pois atrás daquele rosto pode Ter uma maldade. 
A constituição dos modos de perceber a loucura por alunos e egressos do Curso de Graduação em Enfermagem: um estudo com o enfoque da Fenomenologia social

Isso vem da minha familia, dos próprios colegas contando histórias de que foram atacados por doentes mentais, que fizeram maldades com eles.." (e. Eg. 9)

O elemento decisivo para a constituição da percepção de ambos os grupos que compõe os sujeitos desta pesquisa, tem sua matriz nas vivências infantis, subsidiando a visão que desenvolve a respeito do doente mental, é esperado que as categorias concretas do vivido de alunos e egressos sejam semelhantes nos enfoques decorrentes dessas experiências.

No que se refere a uma percepção do indivíduo adoecido mentalmente como uma pessoa diferente, encontramos nos discursos dos egressos a seguinte verbalização:

"Essa idéia do doente mental, pra mim ficou assim, sempre no tempo de criança, se alguém tem comportamento diferente, ah aquele é doido! Ou se ele está fora daquele padrão já preestabelecido, então, ele age diferente, ele é doente, ele não pensa..." (e.eg. 10)

Os discursos dos egressos que apresentam o doente mental como uma pessoa que mobiliza sentimentos de medo, dó e compaixão são consistentes. Ao mesmo tempo, anunciam ou complementam seus discursos com uma outra vertente de percepção, da qual foram originadas suas categorias específicas do concreto vivido, que em seu bojo traduzem as modificações decorrentes das experiências do aprendizado acadêmico vivenciado, que serão apresentadas posteriormente. Em muitos aspectos, seus discursos mostram-se semelhantes aos dos alunos.

"Uma pessoa descontrolada que, na maioria das vezes, a gente não tem domínio sobre a doença, causa medo..." (e.eg. 6)

Em relação à expressão de idéias preconceituosas sobre o doente mental, que o colocam em uma situação de exclusão social, os egressos manifestaram-se:

"Acho que antes de eu ingressarna Faculdade eu tinha a mesma idéia que toda sociedade tem, de que era uma pessoa marginalizada, perigosa, uma pessoa que não pode ter muita confiança..." (e. Eg. 3)

As categorias até aqui descritas, que foram organizadas baseadas na análise da fala dos alunos e reafirmadas no discurso dos egressos, representam a "atitude natural" desses sujeitos no "mundo da vida" que, segundo Wagner ${ }^{(6)}$, embasado em Schutz pode ser explicado pelo "o mundo intersubjetivo que existia muito antes do nosso nascimento, vivenciado e interpretado por outros nossos predecessores, como um mundo organizado. Ele agora se dá a nossa experiência e interpretação. Toda interpretação desse mundo se baseia num estoque de experiências dele, as nossas próprias e aquelas que nos são transmitidas por nossos pais e professores, as quais, na forma de "conhecimento a mão funcionam como um código de referência".

A constituição das categorias concretas do vivido dos egressos surge retratando uma ampliação do código de referência desses sujeitos, no qual o doente mental passa a ser percebido dentro de uma nova lógica como pessoa que precisa de ajuda. Nesta ocasião, desenvolvem uma reelaboração da percepção que denota nova compreensão do doente mental.

A realizar as primeiras leituras sobre os depoimentos dos egressos da Faculdade de Enfermagem, tem-se a impressão que a percepção destes em relação ao doente mental é a mesma dos alunos, no entanto, nas subseqüentes, há o desvelamento de um outro sentido extremamente significativo embutido nesse discurso, passam a ter uma visão mais humana do doente mental. Aí ele é visto como uma pessoa que precisa de ajuda e, ao mesmo tempo, quase que justificando uma atitude contrária, falam sobre a dificuldade de se relacionar com essa pessoa com comportamentos inesperados, sentindo-se despreparados para assisti-lo, expressam se também mais espontaneamente sobre o processo de identificação tão mitigado, tão proibido inconscientemente até terem tido a experiência de aprendizado acadêmico, que envolve matizes da normalidade e da loucura.

Pessoa que precisa de ajuda, representa a categoria constituída com base na seguinte expressão:

“...eu não tenho medo da pessoa, eu acho que elas precisam de muita ajuda, a minha vontade mesmo quando a pessoa que está extremamente descontrolada, que precisa, ainda mais quando eu as conheço, é vontade de ajudá-las a estarem tentando superar isso da melhor forma possivel." (e. Eg. 5)

A categoria Reelaboração da Percepção foi baseada nas falas dos egressos da Faculdade de Enfermagem que retratam uma nova visão do doente mental. Em muitas falas percebe-se que houve alteração concomitante da percepção e das emoções que permeavam suas elaborações iniciais em relação ao doente mental, em outras um discurso modificado, mas com a permanência do sentimento que representou a base de suas percepções - o medo. Pela relevância destes discursos, na obtenção dos "motivos para", o próximo fragmento de suas falas é ressaltado por expressar o significado que teve 0 aprendizado da disciplina Enfermagem Psiquiátrica na reelaboração de suas percepções:

“...sim, na verdade, você consegue entender o ser humano e ele não é louco, ele tem uma doença que precisa necessariamente ser tratada, e tudo isso interfere em todos os processos fisiológicos e orgânicos do indivíduo, por isso que ele tem certos tipos de reações. Então, a partir do conhecimento faz com que você consiga entendê-lo e tratá-lo melhor, pra que você não o isole, pra que você compreenda o porquê ele está naquela forma, assim não vai Ter porque Ter medo, você vai Ter como ajudá-Io." (e. Eg.1)

A vivência de aprendizado proporcionada pelo ensino formal da disciplina Enfermagem Psiquiátrica possibilita ao egresso uma ampliação de conhecimento, um enriquecimento que o leva a modificar a percepção que tem do doente mental.

Esta transformação que ocorre baseada em uma mudança conceitual sobre a doença mental, se ficar estagnada como uma vivência isolada, circunscrita em um tempo, não terá representatividade transformadora. Como experiência delimitada, ela não tem potencial transformador frente aos conhecimentos adquiridos nas relações estabelecidas no transcorrer de sua vida com predecessores significativos e o meio social, já que estes agentes mantêm-se ativos com esta mesma bagagem de conhecimentos.

Estas situações descritas representam em sua essência os "motivos porque" e os "motivos para" destes sujeitos, retratam suas intenções em relação ao doente mental. Assim, se os "motivos porque" remetem às experiências passadas, o que é motivado em uma ação do modo "porque" é o projeto dela em si. Os comportamentos medo, preconceito, rejeição são motivados nas vivências passadas, decorrentes da história de vida, da sedimentação de significados transmitidos. Isto significa que influenciaram de forma determinante a constituição da percepção que o egresso tem do doente mental. Por ser uma categoria objetiva, somente em retrospectiva, 0 ator pode apreender os "motivos porque" genuínos de seu ato. O egresso, só após vivenciar a situação de aprendizado, e responder a questionamentos que o remeteram ao passado, pode reconstruir ou captar seus genuínos "motivos porque".

Os "motivos para" ou a "fim de" referem-se a uma classe que tem motivação voltada ao futuro, isto é, o estado de coisas pré-imaginado que será acarretado pela ação futura. 0 "motivo para" relaciona-se, portanto, à atitude do ator que vive o processo de sua ação em curso, o que o torna 
uma categoria, essencialmente, subjetiva, que só será revelada ao observador se ele perguntar qual o significado que 0 ator atribui à sua ação.

Os "motivos para" do egresso emergem da vivência de aprendizado, impulsionando-os para novas ações que são conseqüentes de uma alteração de percepção. Passam a tipificar o doente mental dentro de uma outra ordem de valores ao reconhecê-lo como uma pessoa que precisa de ajuda por vivenciar a experiência de adoecimento psíquico. A vivência de aprendizado faz com que eles planejem uma assistência ao doente mental embasada em conhecimento, realizada em contextos que o respeitem e auxiliem em seu desenvolvimento e que o reconheçam como pessoa de direito. Assim sendo, das categorias concretas do vivido do egresso foi elaborado seu tipo vivido.

O egresso, após ter vivenciado o processo ensino-aprendizado na disciplina Enfermagem Psiquiátrica retrata um tipo vivido que percebe 0 doente mental como pessoa que precisa de ajuda e que reelabora sua percepção considerando que, a falta de conhecimentos e de recursos psíquicos e emocionais dos profissionais, da família e da sociedade são favorecedoras da segregação e exclusão do doente mental e, por meio das atitudes desenvolvidas por pessoas adoecidas assistidas dentro de um novo paradigma, alteram suas percepções, em especial, a visão preconceituosa.

\section{CONSIDERAÇÕES FINAIS}

\section{Vislumbrando novos caminhos}

Consideramos que, por meio do conteúdo apreendido dos discursos desta pesquisa, a transformação da percepção sobre o doente mental passa, necessariamente, pela assimilação dos princípios do novo paradigma que embasa a Reforma Psiquiátrica Brasileira em implantação. Visto que ela reconhece e trata a pessoa adoecida mentalmente sob outros eixos conceituais que a percebem como pessoa de direito e, portanto, ampliam sua contratualidade social, possibilitando uma nova forma de inserção e reintegração social, condições imprescindíveis à retomada de cidadania. Arcabouço que propicia ao doente mental uma condição menos estigmatizante.

Por outro lado, as demais formas de comunicação em massa que ocorrem por meio do cinema, televisão, como exemplo, trabalham a representação do doente que foi originada no velho paradigma, estimulando o medo, o preconceito e a rejeição ao doente mental.

No processo ensino-aprendizagem reconhecemos um grande potencial transformador, uma vez que este aspecto faz parte de sua essência. As escolhas feitas e implementadas por um processo educacional retratam um comprometimento ideológico, pois elas nunca são neutras.

Se a questão premente deste estudo foi desvelar como ocorre a constituição da percepção que alunos e egressos da graduação de enfermagem têm do doente mental e conhecer como o ensino pode interferir nela, faz-se importante pontuar que, enquanto ele apresentar ambigüidade e pouca consistência no que tange à assimilação dos preceitos do novo paradigma, apresentará uma eficácia transformadora circunscrita a uma visão mais humana e acolhedora, por um período de tempo. Se na prática assistencial não ocorrerem transformações acentuadas, a miscigenação de vivências acabará por acionar a bagagem de conhecimentos que estes sujeitos trazem de sua história biográfica e ela predominará sobre ações, informações, conhecimentos que não encontram substratos no mundo da vida cotidiana.

Há um grande caminho a ser percorrido por todos que se comprometerem a participar desta construção que se propõe possibilitar ao doente mental uma condição de viver cidadã, como um sujeito de direito no mundo da vida.

Neste momento, referendamos o que cita Amarante ${ }^{(9)}$ : para transformar esta realidade, é necessário sair do território exclusivamente psiquiátrico e construir na sociedade as condições para que ela, como espaço real da vida humana participe da solução.

Acreditamos que só o ensino não dará conta de transformar a percepção constituída em relação ao doente mental, por outro lado a concepção que embasar este ensino será determinante a respeito do modo de perceber e relaciona-ser com ele.

Consideramos, ainda, que a vivência da construção deste estudo possibilitou-nos uma visão mais ampliada e comprometida com o processo de cuidar e, sobretudo, de ensinar a cuidar. Possibilitou-nos também compreender o momento ímpar que a sociedade brasileira passa no que concerne aos encaminhamentos da assistência à saúde mental e do nosso papel de docente neste contexto como agente de transformação.

\section{REFERÊNCIAS}

1. Goodwin AM, Gore V. Managing the stress of nursing people with severe and enduring mental illness: a psycodynamic observacion study of a long-stay psychiatric waral. $\mathrm{Br} \mathrm{J}$ Med Psychol 2000; 73(Pt 3):311-25.

2. Schutz A. El problema de la realidade social. Buenos Aires (ARG): Amorrortu; 1974.

3. Merighi MAB. Trajetória Profissional de Enfermeiras Obstétricas egressas da Escola de Enfermagem da Universidade de São Paulo. Rev Latino-am Enfermagem 2002;10(5):644-53.

4. Capalbo C. Metodologia das ciências sociais: a fenomelogia de Alfred Schutz. Londrina (PR): UEL; 1998
5. Schutz A. Fenomenologia del mundo social. Buenos Aires (ARG): Paidos; 1972.

6. Wagner HR. Fenomenologia e relações sociais: textos escolhidos de Alfred Schutz. Rio de Janeiro (RJ): Zahar; 1979.

7. Gorman RA. A visão dual: Alfred Schutz e o mito da Ciência Social Fenomenológica. Rio de Janeiro (RJ): Zahar ; 1979.

8. Corrigan PW, Watson AC. Understanding the impact of stigma on people with mental illness. World Psychiatric 2002;1(1):16-20.

9. Amarante P. Psiquiatria social e Reforma Psiquiátrica. Rio de Janeiro (RJ): Fiocruz; 1994 